\title{
STUDY OF THE DEACTIVATION OF A COMMERCIAL CATALYST FOR ETHYLBENZENE DEHYDROGENATION TO STYRENE
}

\author{
I. Rossettia ${ }^{a}$ E. Bencinib ${ }^{\text {, L. Trentinib }}{ }^{\text {and L. Forni }{ }^{\star \star}}$ \\ a Dipartimento di Chimica Fisica ed Elettrochimica, Università degli Studi di Milano \\ Via C.Golgi, 19 I-20133 Milano, Italy \\ b Polimeri Europa S.p.A., v. Taliercio, 14 I-46100 Mantova, Italy
}

\section{ABSTRACT}

The catalytic performance and characteristics of an industrial catalyst, as prepared and spent, i.e. downloaded from an industrial reactor after a normal lifetime cycle, were compared. Some different causes of catalyst deactivation, such as loss or redistribution of promoters, active phase modification, $\mathrm{Fe}^{3+}$ reduction, coke deposition on catalyst surface and physical modifications were evidenced by means of several techniques. All the mentioned causes of deactivation showed strictly interconnected and concurred to the decrease of conversion. However, the key factors leading to irreversible deactivation showed potassium migration towards the inner part of the extrudate particle, its agglomeration into concentrated spots and its volatilisation from the surface, together with the progressive $\mathrm{Fe}^{3+}$ reduction to $\mathrm{Fe}^{2+}$. These modifications led to the enhancement of coking activity and to the loss of mechanical properties, so making deactivation irreversible.

Keywords: Ethylbenzene dehydrogenation; Catalyst deactivation.

* Corresponding author: Fax+39-02-50314300, e-mail: lucio.forni@unimi.it 


\section{INTRODUCTION}

Styrene is one of the most important intermediates of the chemical industry, with a production exceeding 20 million tons/year. Besides that co-produced in the propylene oxide process, up to $80 \%$ of styrene is commercially produced through the catalytic dehydrogenation of ethylbenzene. The reaction is limited by equilibrium, heavily endothermic and it is carried out in either adiabatic or isothermal mode in fixed bed reactors, over promoted Fe-based catalyst. Temperature is usually around $600^{\circ} \mathrm{C}$ and steam is co-fed with the reactant in order to supply heat, to help maintaining the active phase in the correct oxidation state and to prevent or limit catalyst deactivation by coking.

An extensive body of work has been published, aiming at clarifying the nature of the active phase and the role of promoters [1]. Indeed, the catalyst precursor is $\mathrm{Fe}_{2} \mathrm{O}_{3}$ (hematite), which however is not believed to be the real active phase for the present reaction. Many promoters are usually added to confer specific properties, such as $\mathrm{Cr}_{2} \mathrm{O}_{3}$, $\mathrm{MoO}_{3}, \mathrm{~V}_{2} \mathrm{O}_{5}, \mathrm{CeO}_{2}$ [2-4]. Other promoters, such as alkali-earth oxides or even Portland cement act as structural agents to improve mechanical strength [5-7]. However, an increase of catalytic activity up to one order of magnitude can be attained only by adding a consistent amount of $\mathrm{K}\left(10-30\right.$ wt\%), mainly as $\mathrm{K}_{2} \mathrm{CO}_{3}[2,8]$. The effect of $\mathrm{K}$ on catalytic activity has been deeply studied, and it was demonstrated that it has a multifunctional role. The most important finding is that $\mathrm{K}$ is involved in the formation of $\mathrm{KFeO}_{2}$, through reaction with the Fe-precursor, leading to what is believed to be the real active phase for the reaction. This hypothesis was first addressed by Hirano et al. [5,8], later confirmed and modelled by Muhler et al. [9], who invoked also the presence of an additional $\mathrm{K}_{2} \mathrm{Fe}_{22} \mathrm{O}_{34}$ phase, acting as $\mathrm{K}$-supplier for the active $\mathrm{KFeO}_{2}$ species. More recently, inverted roles for these two phases were hypothised $[10,11]$. 
Besides its effect on catalytic activity, the role of $\mathrm{K}$ is fundamental also to prevent or limit catalyst deactivation [1]. The latter is usually attributed to four causes, often interacting with each other: a) coke formation, b) promoters' loss or redistribution, c) $\mathrm{Fe}^{3+}$ reduction and $d$ physical degradation. Among these, coking can be strongly limited by $\mathrm{K}$ addition, $\mathrm{KOH}$ and $\mathrm{K}_{2} \mathrm{CO}_{3}$ being active for the gasification of carbonaceous deposit $[5,12$ 14], and $\mathrm{Fe}^{3+}$ reduction can be prevented as long as $\mathrm{K}$ can be supplied from $\mathrm{K}_{2} \mathrm{Fe}_{22} \mathrm{O}_{34}$ to the active $\mathrm{KFeO}_{2}$ phase or vice-versa $[9,10,11,15]$. Hence, the loss or uneven distribution of $\mathrm{K}$ (cause $b$ ) seems the main cause of irreversible deactivation of the catalyst.

In the present work we compared the main physical-chemical properties and catalytic activity of a fresh industrial catalyst with those of a sample of the same catalyst (Süd Chemie AG), downloaded in 1999 from an industrial reactor after a normal lifetime cycle, aiming at analysing the role of the four previously mentioned possible causes of catalyst decay.

\section{EXPERIMENTAL}

\section{Catalyst characterisation}

Crystalline phase identification on both the fresh and spent catalyst was done by $\mathrm{X}$ ray diffraction analysis (powder method), by means of a Philips (mod. 1025) diffractometer, comparing the patterns obtained with literature data [16].

Specific surface area (SSA adsorption/desorption on a Micromeritics ASAP 2010 instrument. Hg porosimetry was employed to determine meso- and macroporosity, by means of a Micromeritics Autopore3 instrument.

Elemental analysis was carried out by means of a Jordan Valley (mod. EX 310) Xray spectrofluorimeter. In order to obtain the average composition of the sample, several 
extrudates were finely ground and the powder pressed to homogeneous pellets (diameter $20 \mathrm{~mm}$ ). To distinguish between shell and core composition of the spent catalyst some extrudates were carefully erased, in order to recover $10 \mathrm{wt} \%$ of external layer. Both the erased powder and the ground internal core were then pelletized as described.

The topographic distribution of the elements in the fresh and spent catalyst extrudates (mainly focusing on $\mathrm{K}$ ) was obtained through SEM-EPMA analysis, on a Jeol, mod. JSM-5500LV scanning electron microscope, equipped with a Jeol IXRF EDS2000 electron probe micro-analyser. Sample preparation was carried out by embedding the extrudates in a thermo-hardening resin and erasing the embedded particles either axially or radially with progressively finer and finer diamond-powder-covered paper.

The concentration of $\mathrm{Fe}^{2+}$ was determined by titration with aq. $\mathrm{K}_{2} \mathrm{Cr}_{2} \mathrm{O}_{7}$ of a solution obtained by dissolving a known amount of the spent catalyst with aq. $\mathrm{HCl}$ under inert atmosphere.

Coke content was determined by temperature programmed oxidation (TPO), carried out on a previously described apparatus [17]. Ca. $0.2 \mathrm{~g}$ of spent catalyst powder were loaded into a quartz microreactor and heated by $10^{\circ} \mathrm{C} / \mathrm{min}$ up to $800^{\circ} \mathrm{C}$ in a stream of 10 vol\% $\mathrm{O}_{2}$ (SIAD, purity 99.999 vol\%) in He (SIAD, purity 99.9999 vol\%). Qualitative analysis of the species evolved during the TPO experiment was done by a MKS PPT-C200-MZY quadropolar mass spectrometric (QMS) detector. The amount of oxygen consumed was determined by a HWD detector, after careful calibration. The amount of $\mathrm{C}$ on the spent catalyst was calculated by taking into account the oxygen consumption due to oxidation of $\mathrm{Fe}^{2+}$, determined as described (vide supra).

The radial crushing strength was determined by means of a Crush-BK by MA.TEK. dynamometer. 
Apparatus and procedure for catalytic activity testing

Activity tests have been carried out by means of a continuous, downflow, Incoloy 800 tubular reactor, $9 \mathrm{~mm} \mathrm{ID}$, fitted with a $1.6 \mathrm{~mm}$ OD axial thermowell. Oven temperature was regulated by means of a temperature programmer (Eurotherm, mod. 2408). Water and ethylbenzene (Aldrich, purity $99.5 \mathrm{wt} \%$, further purified by distillation) were fed through two independent pumps (Saphirwerk, mod. MDP2000) and the reactant partial pressure was lowered by co-feeding $\mathrm{N}_{2}$ (SIAD, purity 99,995 vol\%) through a mass flowmeter (Brooks, mod. 5811-N), regulated by a Brooks 5874 control unit. The reaction products were trapped at $-40^{\circ} \mathrm{C}$ at the reactor outlet, by using a Neslab Endocal ULT-80 DD cryogenic unit. The collected organic phase was analysed by means of a Hewlett-Packard, mod 5890 gaschromatograph, equipped with flame ionization detector and a capillary HP Ultra PONA column.

Ca. $2 \mathrm{~g}$ of catalyst, obtained by grinding and sieving to $0.25-0.42 \mathrm{~mm}$ particle size the original estrudates, were loaded in the isothermal middle part of the reactor. The reactor void space over and below the catalyst bed were filled with quartz beads (0.7-1.7 $\mathrm{mm}$ in size). Catalyst activation was carried out in flowing $\mathrm{N}_{2}$ by heating $\left(3.17^{\circ} \mathrm{C} / \mathrm{min}\right)$ up to $350^{\circ} \mathrm{C}$. Water was added to the feed at $350^{\circ} \mathrm{C}$. Temperature was then further increased $\left(1.75^{\circ} \mathrm{C} / \mathrm{min}\right)$ up to $610^{\circ} \mathrm{C}$ and ethylbenzene $(\mathrm{EB})$ was added at $550^{\circ} \mathrm{C}$. Reactant/inert flow rates were set so to obtain $\frac{E B+\mathrm{H}_{2} \mathrm{O}}{E B+\mathrm{H}_{2} \mathrm{O}+\mathrm{N}_{2}}=0.5$ (vol/vol in the gas phase), LHSV $=0.5 \mathrm{~h}^{-1}$ and steam/oil $(\mathrm{S} / \mathrm{O})$ weight ratio $=2$.

\section{RESULTS AND DISCUSSION}

Activity data (Table 1) showed the expected remarkable (more than 15\%) drop of activity for the spent catalyst with respect to the fresh sample, though accompanied by 
some increasing of selectivity (from ca. 93.6 to ca. $95.7 \%$, on average), likely due to the conversion decrease.

\section{Deactivation by coking}

The results of qualitative TPO-QMS analysis of the spent catalyst are reported in Fig.1, where the signals relative to $\mathrm{CO}_{2}$ and $\mathrm{H}_{2} \mathrm{O}$ only are given, since no significant amount of other species was detected. Water was released at relatively low temperature. In particular the broad peak around $100^{\circ} \mathrm{C}$ can be attributed to adsorbed process water, while the narrower peak at $180-200^{\circ} \mathrm{C}$, corresponding to a parallel evolution of $\mathrm{CO}_{2}$ was attributed to the contribution of relatively light carbonaceous compounds $\left(\mathrm{CH}_{\mathrm{x}}\right)$. The further evolution of $\mathrm{CO}_{2}$, occurring between 600 and $700^{\circ} \mathrm{C}$, accompanied by an almost undetectable release of water, was attributed to heavily polymerised carbonaceous material, formed directly during catalyst coking or maybe during the oxidation of the lighter carbonaceous compounds, as suggested in [18]. The quantitative calculation of oxygen consumption, based on TPO-HWD and taking into account the contribution of $\mathrm{Fe}^{2+}$ reoxidation to $\mathrm{Fe}^{3+}$ (vide infra), showed an amount of deposited carbon containing compounds of $10.4 \mathrm{wt} \%$.

The rate of coke deposition during EB dehydrogenation depends on many factors, among which steam/oil ratio and reaction temperature play the most important role. Indeed, an excessively high operation temperature enhances the cracking side reactions, occurring on the acidic surface sites of the catalyst. On the other hand, the simultaneous gasification of coke by steam, during normal activity, usually leads to a 3-6 wt\% steadystate concentration of carbonaceous deposits $[13,14]$. The steam gasification of C leads first to $\mathrm{CO}$ and then to $\mathrm{CO}_{2}$, through the shift reaction. The presence of steam helps also in preventing $\mathrm{Fe}^{3+}$ reduction, leading to the subsequent formation of $\mathrm{Fe}_{3} \mathrm{C}$, which is considered a key intermediate in coke formation [12]. 


\section{Loss and redistribution of $K$}

The results of XRF analysis of both the fresh and spent catalyst are reported in Table 2, expressed as average composition of each sample and as surface composition of the spent catalyst, calculated on the erased external layer of the extrudates. The concentration of $\mathrm{Ce}$ and Mo ions promoters remained practically unchanged after catalyst use. A ca. $3 \%$ enrichment of $\mathrm{Ce}$ at the surface can be calculated by comparing the bulk and surface composition of the spent sample (effect of $\mathrm{Ce}$ increase should be due to decrease of K). The surface enrichment of Mo showed much higher (ca. 24\%), likely due to Mo migration by formation of oxyhydroxides. Solid state migration of these ions is indeed rather slow, due to their high atomic weight. A small drop of the overall $\mathrm{Ca}$ concentration can also be observed in the spent catalyst. However, the most dramatic result is the strong loss of $\mathrm{K}$, whose concentration was more than 25 wt\% lower in the spent sample. Furthermore, a considerable redistribution of $\mathrm{Ca}$ was observed, its surface concentration in the spent catalyst being by over $60 \%$ higher than in the bulk. A similar effect, but in the opposite direction showed much more evident for $\mathrm{K}$, which not only was lost by over $25 \mathrm{wt} \%$ through volatilisation, but also tended to concentrate preferably in the bulk of the extrudates.

Potassium distribution in the axial and radial sections of fresh and spent catalyst are shown in Fig.2, white spots representing potassium. Fresh catalyst was characterised by uniform distribution of $\mathrm{K}$ in both axial and radial directions (Fig.2a,b), while in spent catalyst (Fig.2c,d) potassium has migrated within the particle, simultaneously forming highly concentrated spots. This can be seen even in the SEM images of the spent sample (Fig.3). The volatilisation of $\mathrm{K}$ during the reaction confirmed the XRF results.

The role of $\mathrm{K}$ in the present catalyst is multifunctional. All the alkaline metals are active for carbon gasification, allowing to control catalyst deactivation by coking [19-21]. 
Potassium is the most used among the first group metals, because on one hand the small size of the $\mathrm{Li}^{+}$ion favours a fast interphase diffusion and volatilisation. On the other hand, $\mathrm{Cs}^{+}$is too much active and could decompose also styrene, decreasing reaction selectivity. Furthermore, it was demonstrated $[5,8,9,22]$ that the reaction of $\mathrm{K}_{2} \mathrm{CO}_{3}$ with $\mathrm{Fe}_{2} \mathrm{O}_{3}$ (hematite) leads to the $\mathrm{K}_{2} \mathrm{Fe}_{22} \mathrm{O}_{34}$ phase, which in situ forms the active ferrite $\mathrm{KFeO}_{2}$ superficial phase. In both these ternary compounds iron is present as $\mathrm{Fe}^{3+}$. If $\mathrm{Fe}^{3+}$ partially reduces to $\mathrm{Fe}^{2+}$ (vide infra), a rapid segregation into the almost inactive $\mathrm{Fe}_{3} \mathrm{O}_{4}$ and $\mathrm{KOH}$ separate phases takes place, with a considerable drop in catalytic activity.

The present results confirm the occurring of both these phenomena. On one hand, $\mathrm{K}^{+}$progressively migrates towards the surface and it is irreversibly lost by volatilisation, as confirmed by the overall decrease of $\mathrm{K}$ concentration in the spent catalyst. Indeed, under the usual reaction conditions $\mathrm{KOH}$ (and to a lower extent $\mathrm{K}_{2} \mathrm{CO}_{3}$ ) is rather volatile. On the other hand, when the progressive reduction of $\mathrm{Fe}^{3+}$ to $\mathrm{Fe}^{2+}$ occurs, the active ferrite phase is no more stable, segregated magnetite and $\mathrm{KOH}$ phases start to form in the core of the particle (white spots in Fig.2c) and a K-depleted surface layer forms. Potassium migration towards the particle core is driven by the reaction endothermicity, which determines a negative temperature gradient from the surface to the bulk of the extrudates.

As a result the loss of potassium negatively influences catalytic activity for two main concomitant reasons: the active ferrite phase becomes no more stable and the promoter of coke gasification is partly lost and partly segregated in the core of the particle, where it remains practically useless. As an additional cause, the loss of basic species $(\mathrm{KOH})$ must be considered, which does not neutralise anymore the acidic Fe oxide species, so enhancing catalyst coking.

$\mathrm{Fe}^{3+}$ reduction 
The oxidation state of $\mathrm{Fe}$ in both the catalyst precursor and the active phase is $\mathrm{Fe}^{3+}$. Nevertheless, the reaction atmosphere during styrene production is reductive, possibly leading to $\mathrm{Fe}^{3+}$ reduction to $\mathrm{Fe}^{2+}$. The XRD patterns of the fresh and spent catalyst are reported in Fig.4, which evidenced the phase transformations during reaction. Indeed, the main crystallographic phase constituting the fresh sample is $\mathrm{K}_{2} \mathrm{Fe}_{22} \mathrm{O}_{34}$, together with $\mathrm{Fe}_{2} \mathrm{O}_{3}$ and some $\mathrm{CeO}_{2}$. $\mathrm{KFeO}_{2}$ is hardly observable and actually it was not observed in our analysis, because, besides being extremely diluted, it transforms into amorphous species when exposed to air. However, it can form from $\mathrm{K}_{2} \mathrm{Fe}_{22} \mathrm{O}_{34}$ upon heating $[9,23,24]$. By contrast, the spent catalyst is mainly constituted of $\mathrm{Fe}_{3} \mathrm{O}_{4}$, with minor amounts of $\mathrm{CeO}_{2}$. This clearly confirms the partial reduction of $\mathrm{Fe}^{3+}$ to $\mathrm{Fe}^{2+}$, with formation of the stable magnetite phase. The concentration of $\mathrm{Fe}^{2+}$, determined by titration, was ca. 12.4 wt\%. On this basis an amount of $51.4 \mathrm{wt} \%$ of magnetite can be calculated.

$\mathrm{Fe}_{2} \mathrm{O}_{3}$ reduction to $\mathrm{Fe}_{3} \mathrm{O}_{4}$ through the formation of $\mathrm{K}_{2} \mathrm{Fe}_{22} \mathrm{O}_{34}$ is known to occur during the normal cycle of activity $[6,25,26,27]$. Former studies on the nature of the active phase $[9,15]$ allowed to define $\mathrm{KFeO}_{2}$ as the real active phase, stable in the reaction environment, although very recently a $\mathrm{K}$-reservoir role for $\mathrm{KFeO}_{2}$ has been hypothised, giving to $\mathrm{K}_{2} \mathrm{Fe}_{22} \mathrm{O}_{34}$ the role of active phase $[10,11]$. Independently from the exact attribution, both the active phase, constituted by $\mathrm{Fe}^{3+}$, and $\mathrm{Fe}_{2} \mathrm{O}_{3}$ slowly reduce to magnetite, but the active component can be steadily replaced as long as the mixed Fe-Kcontaining phase is present. So it can be concluded that deactivation due to $\mathrm{Fe}^{3+}$ reduction is not irreversible until $\mathrm{Fe}^{3+}$ can be continuously supplied at the expenses of $\mathrm{K}_{2} \mathrm{Fe}_{22} \mathrm{O}_{34}$ or $\mathrm{KFeO}_{2}$. When the latter vanishes and this is accompanied by other deactivation causes, such as $\mathrm{K}$ loss/redistribution (vide supra), deactivation becomes irreversible and the catalytic activity decreases faster and faster. 
Modification of physical characteristics of the catalyst

The EB dehydrogenation reaction being strongly endothermic, high reaction temperature (around $600^{\circ} \mathrm{C}$ ) is needed, in order to attain industrially interesting conversions. Under such conditions the catalyst undergoes thermal stress which could cause sintering and structural and phase modification, so altering the mechanic properties.

The SSABET of commercial catalyst is usually quite low. The present fresh sample showed $S_{S A} A_{B E T}=2.8 \mathrm{~m}^{2} / \mathrm{g}$ and pore volume $=0.014 \mathrm{~cm}^{3} / \mathrm{g}$. Prolonged use at high temperature caused a further decrease of surface area to $1.3 \mathrm{~m}^{2} / \mathrm{g}$ and of porosity to 0.005 $\mathrm{cm}^{3} / \mathrm{g}$. Nevertheless, a parameter of high importance is macroporosity, which can strongly influence reaction selectivity. Indeed, diffusional limitations could entrain a too high contact time of the reactant with surface acidic sites, so promoting excessive cracking sidereactions. $\mathrm{Hg}-\mathrm{He}$ porosimetry allowed to determine a rather narrow pore size distribution, centred around $0.35 \mu \mathrm{m}$ for the fresh catalyst. Partial collapse of the structure probably occurred during use, as can be evidenced by a shift of the medium pore size to ca. 0.55 $\mu \mathrm{m}$ for the spent catalyst. A small decrease of the bulk density was also observed, from $1.28 \mathrm{~g} / \mathrm{cm}^{3}$ for the fresh catalyst to $1.25 \mathrm{~g} / \mathrm{cm}^{3}$ for the spent sample.

The mechanical strength of the industrial catalyst is an important parameter, to be optimised by proper extrusion of the active phase. An interesting investigation on this point has been carried out on the rheological properties of extruded honeycombs to be used for the present reaction [28]. However, mechanical stability has to be guaranteed during use, checking the possible causes giving rise to a decreasing catalyst strenght. $\mathrm{Fe}^{3+}$ progressive reduction to $\mathrm{Fe}^{2+}$ entrains several interconnected deactivation phenomena, together with a change of mechanical properties of the catalyst. Indeed, phase transition from hematite to magnetite causes a transformation of crystal lattice structure from hexagonal to cubic (Fig.4), accompanied by a modification of mechanical strength, as 
evidenced by a considerable change of the radial crushing strength from fresh to spent catalyst extrudates (Fig.5). Data distribution for the fresh sample is quite narrow and centred around a value of $6 \pm 1 \mathrm{~kg}$. By contrast, for the spent catalyst a much wider distribution of crushing strength data can be observed, leading to an average value of $5 \pm 3$ $\mathrm{kg}$, with a noticeable amount of data as low as $2-3 \mathrm{~kg}$.

The deterioration of the mechanical resistance, besides to the mentioned phase transition from hematite to magnetite, with the simultaneous transformation of the crystal lattice, can be attributed also to the agglomeration of $\mathrm{K}$ into the previously mentioned spots (Fig. 2,3), which causes a change of the particle local density. Whatever the cause, the decrease of mechanical strength entrains catalyst pulverisation, with increasing reactants pressure drop along the bed and modification of the local bed density and of the reactants flow regime. This is usually accompanied by a decrease of selectivity and conversion.

\section{CONCLUSIONS}

The deactivation of a commercial catalyst for ethylbenzene dehydrogenation to styrene during a normal life-time cycle was studied. Many causes of the catalyst decay were outlined, often interconnected with each other. First of all, in the spent catalyst a severe loss of potassium occurred, accompanied by segregation of the remaining promoter into concentrated but very likely inactive spots. This negatively affected many other parameters, such as coking prevention activity and stability of the active phase. Deposition of carbon containing compounds on the catalyst surface attained $10 \mathrm{wt} \%$ and it can be addressed as a concomitant cause of deactivation, becoming important when potassium loss and redistribution becomes irreversible. Progressive reduction of $\mathrm{Fe}^{3+}$ to $\mathrm{Fe}^{2+}$ determined the loss of catalyst active phase, which became irreversible after a potassium-storage phase completely vanished. Finally, a deterioration of mechanical 
properties was evident, due both to phase transition during hematite reduction to magnetite and to potassium segregation.

\section{ACKNOWLEDGEMENT}

We thank Polimeri Europa SpA, Mantova and Süd Chemie AG, München for the permission to publish this paper.

\section{REFERENCES}

[1] - G.R. Meima, P.G. Menon, Appl. Catal. A: General, 212 (2001) 239.

[2] - F. Cavani, F. Trifirò, Appl. Catal. A: General, 133 (1995) 219.

[3] - W.J. Pöpel, W. Büchele, A. Deimling, H. Petersen, DE Pat. No.4,324,905 A1 (1995), to BASF AG.

[4] - G.E. Lewis, A.R. Smith, F.A. Sherrod, US Pat. No. 4,804,799 (1989), to Dow Chemical.

[5] - T. Hirano, Bull. Chem. Soc. Jpn., 59 (1986) 2672.

[6] - E.H. Lee, Catal. Rev., 8 (1973) 285.

[7] - P.W. Dellinger, R.G. Moore, F.A. Sherrod, A.R. Smith, US Pat. No. 5,376,613 (1994), to Dow Chemical.

[8] - T. Hirano, Appl. Catal, 26 (1986) 65.

[9] - M. Muhler, J. Schutze, M. Wesemann, T. Rayment, A. Dent, R. Shlögl, G. Ertl, J. Catal., 126 (1990) 339.

[10] - O. Shekhah, W. Ranke, R. Schlögl, J. Catal., 225 (2004) 56.

[11] - O. Shekhah, W. Ranke, A. Schüle, G. Kolios, R. Schlögl, Angew. Chem. Int. Ed., 42 (2003) 5760.

[12] - R.A. Buyanov, V.V. Chesnokov, A.D. Afanas'ev, V.S. Babenko, Kinet. Catal., 18 (1977) 839. 
[13] - B.D. Herzog, H.F. Rase, Ind. Ing. Chem. Prod. Res. Dev., 23 (1984) 187.

[14] - K.R. Devoldere, G.F. Froment, Ind. Eng. Chem. Res., 38 (1999) 2626.

[15] - M. Muhler, R. Shlögl, A. Reller, G. Ertl, Catal. Lett., 2 (1989) 201.

[16] - Selected Powder Diffraction Data, J.C.P.D.S., Swarthmore, PA, Minerals, Files no. 19-629 $\left(\mathrm{Fe}_{3} \mathrm{O}_{4}\right), 26-1319\left(\mathrm{KFeO}_{2}\right), 31-1034\left(\mathrm{~K}_{2} \mathrm{Fe}_{22} \mathrm{O}_{34}\right), 4-593\left(\mathrm{CeO}_{2}\right), 33-664$ $\left(\mathrm{Fe}_{2} \mathrm{O}_{3}\right)$.

[17] - I. Rossetti, N. Pernicone, L. Forni, Appl. Catal. A: General, 248 (2003) 97.

[18] - M. Guisnet, P. Magnoux, Catal. Today, 36 (1997) 477.

[19] - C.A. Mims, J.J. Chludzinski, J.K. Pabst, R.T.K. Baker, J. Catal., 88 (1984) 97.

[20] - D.E. Stobbe, F.R. van Buren, A.J. van Dillen, J.W. Geus, J. Catal., 135 (1992) 533.

[21] - D.E. Stobbe, F.R. van Buren, A.J. van Dillen, J.W. Geus, J. Catal., 135 (1992) 548.

[22] - J. Lundin, L. Holmlid, P.G. Menon, L. Nyborg, Ind. Eng. Chem. Res., 32 (1993) 2500.

[23] - N.V. Dvoretskii, E.G. Stepanov, T.N. Suddziloskaya, G.R. Koltel'nikov, V. Yun, Inorg. Mater., 25 (1989) 242.

[24] - J. Subrt, J. Vins, I.S. Shapygin, A.A. Zakharov, Thermochim. Acta, 93 (1985) 489.

[25] - Ph. Courty, J.F. Le Page, Stud. Surf. Sci. Catal., 3 (1979) 293.

[26] - X. Yang, S. Weng, K. Jiang, L. Mao, Y. Euong, K. Jing, Hyperfine Interactions, 69 (1991) 863.

[27] -X.M. Zhu, M. Schön, U. Bartmann, A.C. van Veen, M. Muhler, Appl. Catal. A: General, 266 (2004) 99.

[28] - W.P. Addiego, W. Liu, T. Boger, Catal. Today, 69 (2001) 25. 
TABLE 1: Conversion (C) of ethylbenzene and molar selectivity to styrene, toluene and benzene ( $S_{S}, S_{T}$ and $S_{B}$, respectively) over fresh and spent catalyst.

\begin{tabular}{|c|c|c|c|c|c|c|c|c|}
\hline & \multicolumn{4}{|c|}{ Fresh catalyst } & \multicolumn{4}{c|}{ Spent catalyst } \\
\hline Time-on-stream & $\mathbf{C}$ & $\mathbf{S}_{\mathbf{S}}$ & $\mathbf{S}_{\mathbf{T}}$ & $\mathbf{S}_{\mathbf{B}}$ & $\mathbf{C}$ & $\mathbf{S}_{\mathbf{S}}$ & $\mathbf{S}_{\mathbf{T}}$ & $\mathbf{S}_{\mathbf{B}}$ \\
\hline 18 & 77.6 & 93.9 & 4.3 & 1.8 & 63.1 & 95.5 & 3.2 & 1.3 \\
\hline 24 & 77.6 & 94.1 & 4.2 & 1.7 & 65.7 & 96.0 & 2.8 & 1.2 \\
\hline 42 & 78.5 & 92.9 & 5.3 & 1.8 & 65.9 & 95.9 & 2.9 & 1.2 \\
\hline 48 & 76.3 & 93.4 & 5.3 & 1.7 & 65.2 & 95.4 & 3.3 & 1.3 \\
\hline
\end{tabular}

Table 2: Catalyst composition as determined by XRF analysis. Values expressed as wt\% of the oxide.

\begin{tabular}{|c|c|c|c|}
\hline & Fresh catalyst & Spent catalyst & Spent catalyst (surface) $^{\star}$ \\
\hline $\mathrm{K}_{2} \mathrm{O}$ & 13.0 & 9.7 & 7.8 \\
\hline $\mathrm{CeO}_{2}$ & 11.7 & 12.0 & 12.4 \\
\hline $\mathrm{MoO}_{3}$ & 2.1 & 2.2 & 2.9 \\
\hline $\mathrm{CaO}$ & 1.9 & 1.6 & 2.6 \\
\hline $\mathrm{Fe}_{2} \mathrm{O}_{3}$ & balance & balance & balance \\
\hline
\end{tabular}

* referred to a $10 \mathrm{wt} \%$ external shell erased from the extrudates 


\section{FIGURE CAPTIONS}

Fig. 1: Temperature programmed oxidation of the spent catalyst.

Fig. 2: EPMA analysis on fresh ( $a$ and $b$ ) and spent ( $c$ and $d$ ) catalyst. White spots represent potassium.

Fig. 3: SEM micrographs of the spent catalyst: radial (a) and axial (b) section.

Fig. 4: XRD pattern of fresh and spent catalyst.

Fig. 5: Crushing strength data for fresh and spent catalyst. 
Fig. 1

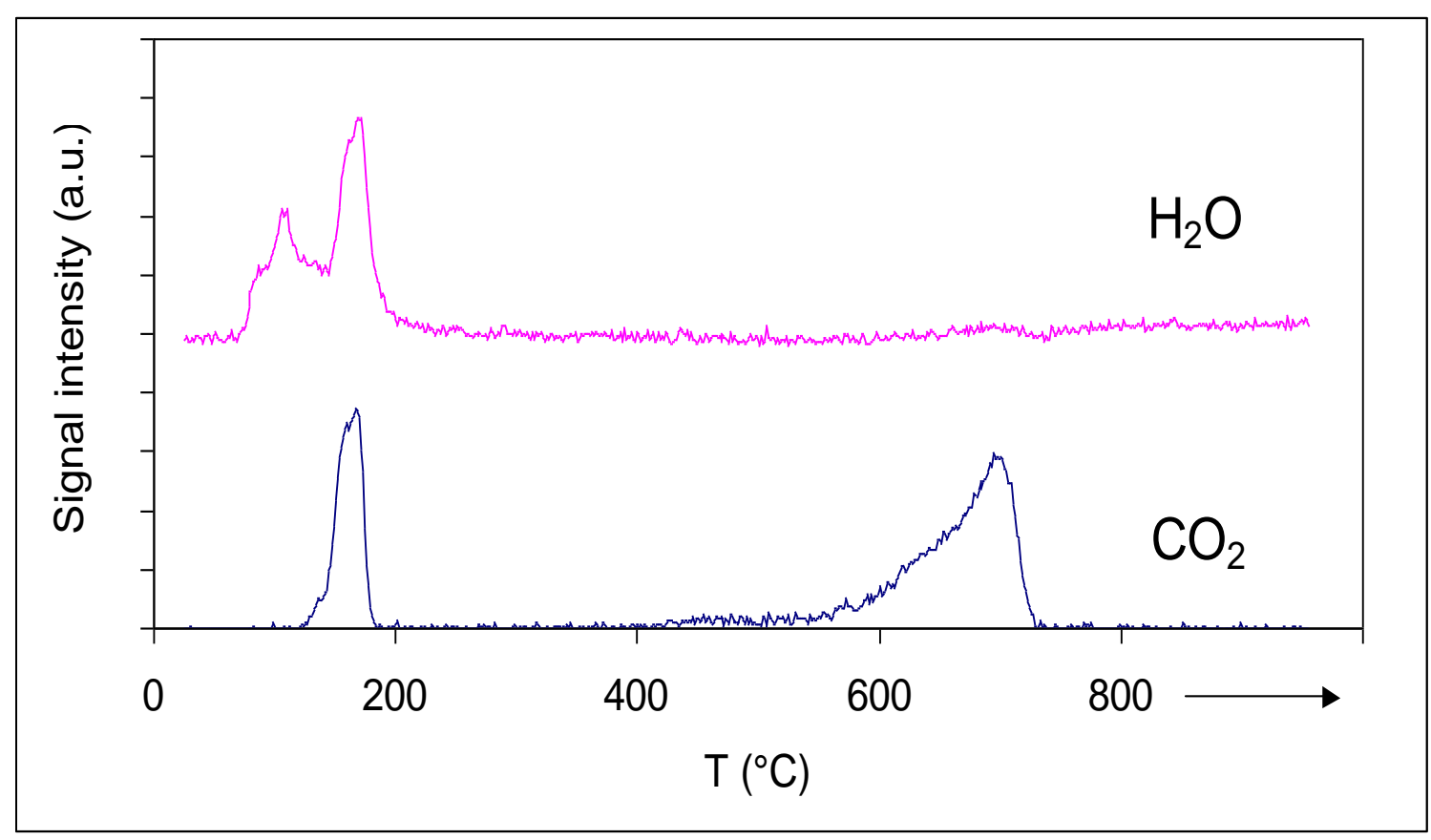




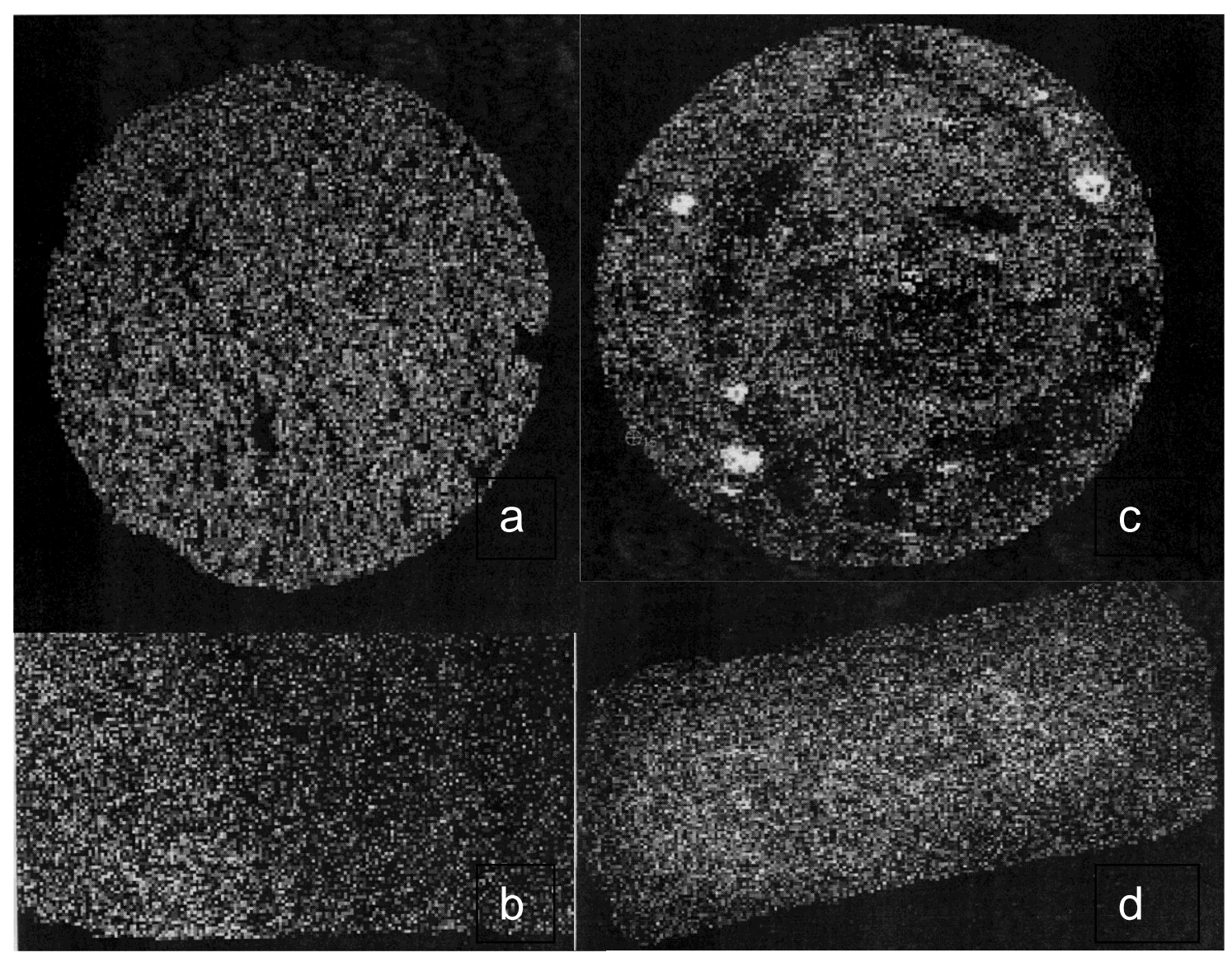

Fig.3
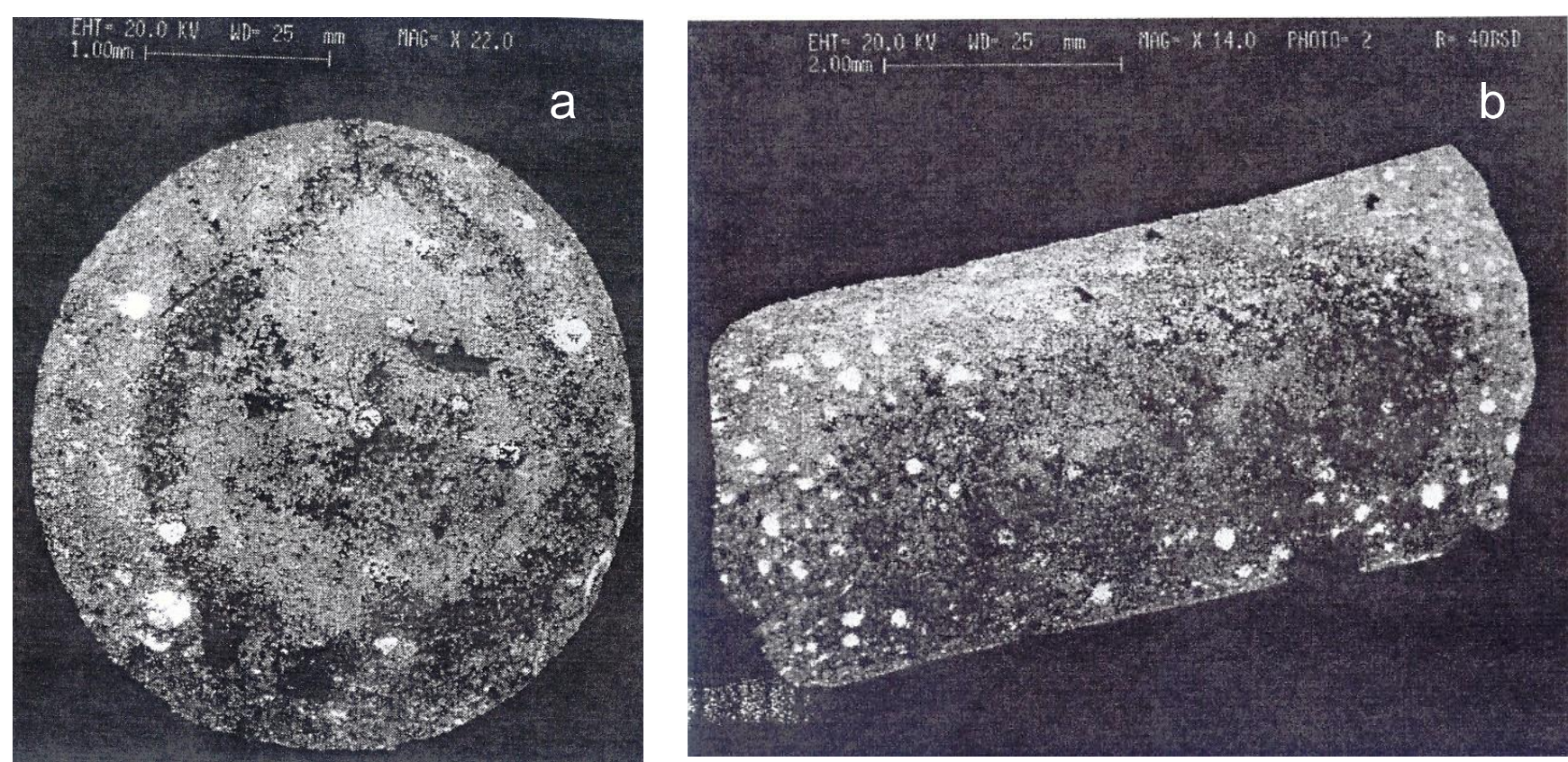

EHT $20.0 \mathrm{~kW}$ WD $25 \mathrm{~m} \mathrm{nin}$

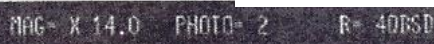


Fig. 4

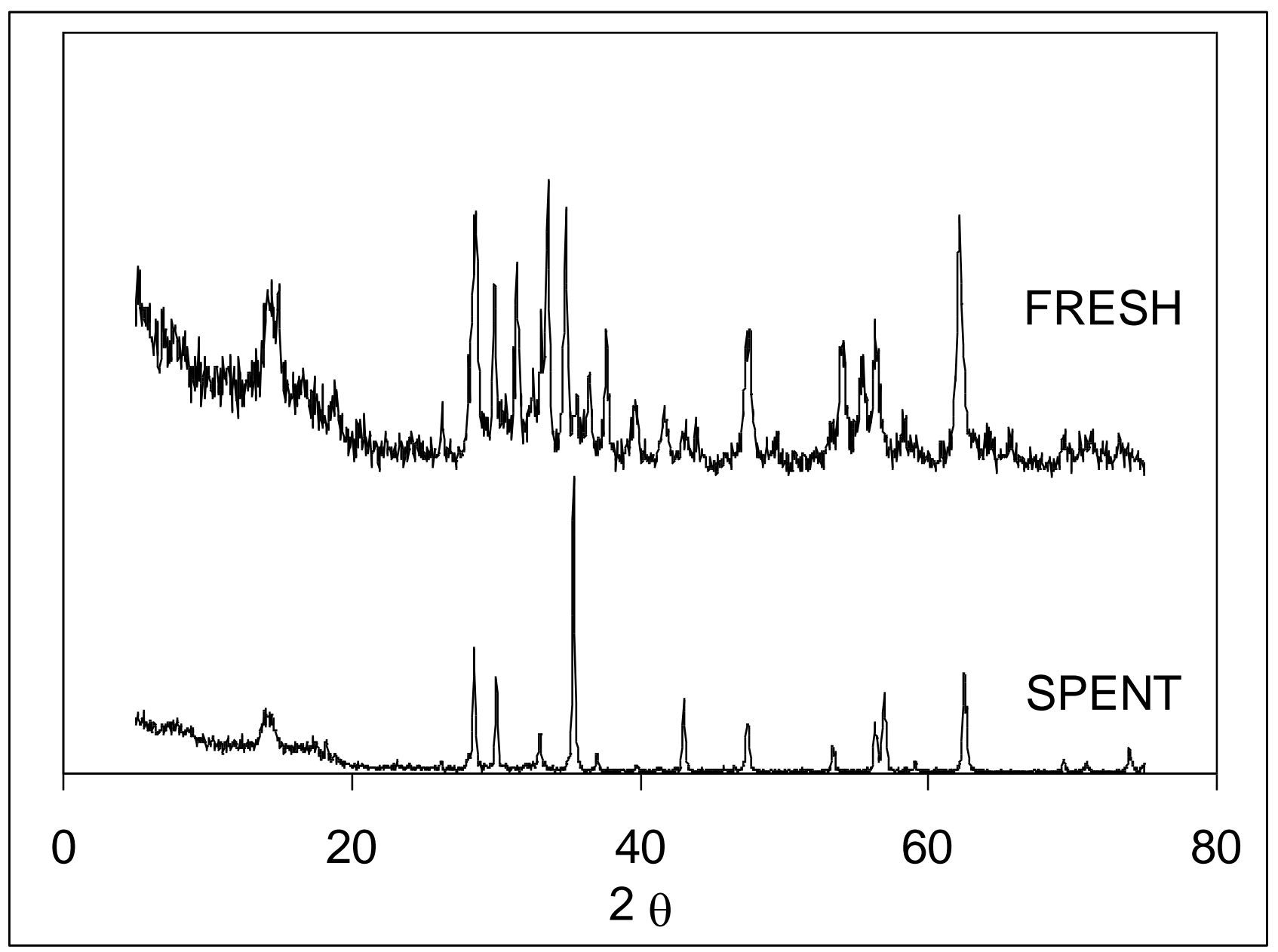


Fig. 5
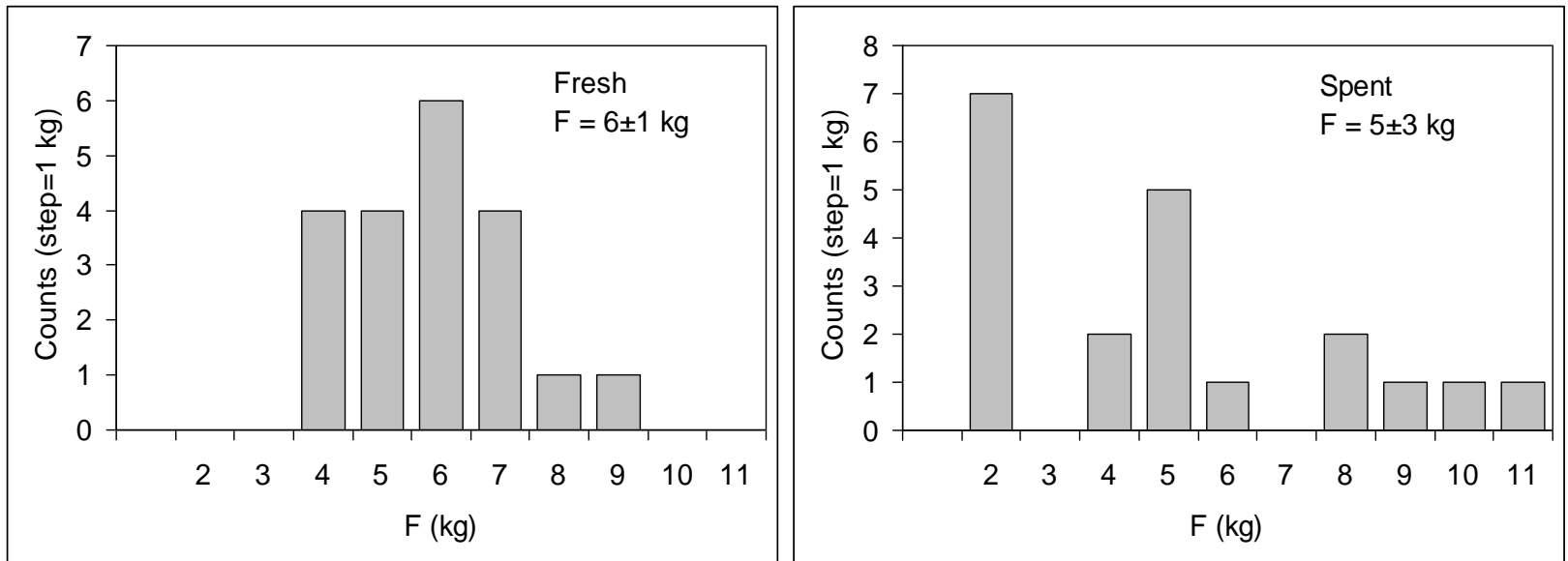